\title{
Maternal diet before and during pregnancy and risk of asthma and allergic rhinitis in children
}

Nour Baï ${ }^{1 *}$ D , Jocelyne Just ${ }^{1,2}$, Julie Chastang ${ }^{1,3}$, Anne Forhan ${ }^{4,5}$, Blandine de Lauzon-Guillain ${ }^{4,5,6}$, Anne-Marie Magnier ${ }^{1,3}$ and Isabella Annesi-Maesano ${ }^{1}$ on behalf of the EDEN Mother-Child Cohort Study Group

\begin{abstract}
Background: Consumption of certain foods during pregnancy has been shown to have beneficial effects on childhood asthma and allergic disease development and aggravation. However, most studies provide conflicting results and the relationships between maternal preconceptional diet and risks of childhood asthma and allergic disease have not previously been explored. The objective of this study was to assess maternal diet during the year before pregnancy and the last 3 months of pregnancy and investigate their associations with the risks of asthma, wheezing, allergic rhinitis and atopic dermatitis in young children.
\end{abstract}

Methods: The study sample consisted of 1140 mother-child pairs from the EDEN cohort. Mothers had responded to the food frequency questionnaires used to assess diet before and during pregnancy. Children were followed up using health questionnaires. The health outcomes studied were: asthma, wheezing, allergic rhinitis and atopic dermatitis by the age of 3 years.

Results: Using multivariable-adjusted logistic regression models, significant inverse associations were observed between cooked green vegetable consumption before pregnancy and childhood asthma; consumption of eggs and raw vegetables before and during pregnancy, consumption of grains before pregnancy, and consumption of cooked green vegetables during pregnancy and allergic rhinitis. For the first time, a significant positive association was found between meat intake during the preconceptional period and a risk of wheezing, allergic rhinitis and atopic dermatitis.

Conclusions: Based on our findings, preconceptional and prenatal maternal intake of certain type of food groups may be preventive against asthma, wheezing and allergic rhinitis, whereas higher maternal intake of meat before pregnancy may increase the risk of wheezing, allergic rhinitis and atopic dermatitis in young children.

Keywords: Diet, Preconception, Pregnancy, Allergic diseases, Wheezing, Allergic rhinitis, Atopic dermatitis, Motherchild cohort

\footnotetext{
*Correspondence: baiz.nour@gmail.com

${ }^{1}$ Epidemiology of Allergic and Respiratory Diseases Department (EPAR),

Pierre Louis Institute of Epidemiology and Public Health (IPLESP UMRS

1136), Saint-Antoine Medical School, Sorbonne Université and INSERM, 27

Rue Chaligny, 75571 Paris Cedex 12, France

Full list of author information is available at the end of the article
} 


\section{Introduction}

The prevalence of allergies and asthma is increasing, suggesting the influence of the environment $[1,2]$. Maternal diet during pregnancy is often considered a possible factor in the development of atopy in children [3]. However, whether gestational diet contributes to protecting their children from asthma and allergic dieases has been poorly investigated and the preconceptional period has not previously been explored. The answer to this question is important because diet is modifiable and it may thus be possible to carry out related public health interventions to prevent the development of asthma and allergic diseases during childhood.

Because prenatal life is a crucial period in immune system development, a number of studies have examined the role of intrauterine exposures in the etiology of allergic diseases [4]. Pregnancy is a physiological situation involving high anabolic activity, requiring sufficient intake of micronutrients, trace elements and vitamins [5]. During gestation, essential nutrients are transferred from the mother into the fetal circulation through the placenta [6]. Consequently, dietary factors associated to allergic diseases likely begin to exercise their influence in utero. In this context, it has been suggested that maternal diet during pregnancy may influence fetal immune responses and thus be involved in predisposition to allergies in childhood [7, 8].

Foods consist of a mixture of nutrients whose combined effects could be greater than the sum of their individual effects, whether or not they protect against asthma and allergic diseases. The consumption of certain foods and food groups by pregnant women has been shown in various studies to have beneficial effects on asthma and allergic diseases [9-12]. However, the relationships between maternal diet before the beginning of pregnancy and risks of childhood asthma and allergic disease have not previously been explored.

It is thus of interest to investigate the relationships of groups of similar foods consumed by the mothers before and during pregnancy to the risks of childhood asthma and allergic diseases. The objective of the present study was to assess maternal dietary intake by food group during the year before and during the last 3 months of pregnancy and to explore the associations between maternal intake of certain categories of foods and the risks of asthma, wheezing, allergic rhinitis and atopic dermatitis in children from the EDEN birth cohort followed-up to the age of 3 years.

\section{Materials and methods Population}

The required data were available for 1140 of the 2002 women included in the EDEN study [13]. Mother-child pairs were recruited in the EDEN Prospective Birth Cohort Study (http://eden.vjf.inserm.fr). The primary aim of the EDEN cohort is to identify prenatal and early postnatal nutritional, environmental, and social determinants associated with children's health and normal and pathologic development. Pregnant women seen for a prenatal visit at the departments of Obstetrics and Gynecology of the University Hospital of Nancy and Poitiers before their 24th week of amenorrhea were invited to participate. Enrollment started in February 2003 in Poitiers and September 2003 in Nancy; it lasted 27 months in each center. Women with speaking and writing abilities in French who did not have type 2 diabetes diagnosed before pregnancy and did not plan to deliver outside the university hospital or move out of the region within 3 years were included in the study. Multiple pregnancies were excluded. Among eligible women, 55\% (2002 women) agreed to participate (1034 women in Nancy and 968 in Poitiers). Of the 2002 mother-child pairs included in the EDEN study, 1140 of them had complete data by the child's age of 3 years. The missing data relate mainly to women who decided to withdraw from the study, women who were lost to follow-up, and miscarriages or fetal deaths. Analyses were performed on results from the 1140 women who responded to the two food frequency questionnaires (FFQs) and completed annual health questionnaires up to age 3 .

\section{Ethics statement}

The ethical committees who approved the study are: Comité Consultatif pour la Protection des Personnes dans la Recherche Biomédicale, Le Kremlin-Bicêtre University hospital, and Commission Nationale de l'Informatique et des Libertés. The study was approved on 12 December 2002. Written consent was obtained from the mother for herself at the beginning of the study and from both parents for the newborn child after delivery.

\section{Maternal dietary assessment}

The FFQ completed by mothers in the EDEN cohort was very similar to the one developed for the FleurbaixLaventie Ville Santé study [14], which was validated using a series of 24-h recalls [15]. The EDEN questionnaire included some additional items about intake of fish and foods rich in folates, $\mathrm{n}-3$ FAs and vitamin $\mathrm{A}$. The FFQ included 137 foods and food groups assessed on a sevenitem scale, from "never" to "more than once a day." The questions concerned both single food items (e.g., lamb chop, lettuce, banana, orange juice) and mixed dishes (e.g., cassoulet, paëlla). Participants had to indicate portion sizes for each food, using a portion-size booklet with photographs of portion sizes for 12 foods and drinks 
(three sizes each), drawn from a manual used in the SU.VI.MAX (SUpplémentation en Vitamines et Minéraux Anti-oXydants [supplementation with antioxidant vitamins and minerals]) study [16]. The questionnaire also included questions on cooking methods and on fats and oils used in cooking and seasoning. For other foods, the portion consumed was assumed to be a standard portion assessed for the French adult population [17]. To calculate the food intake for each item, the portion consumed (in g) was multiplied by the frequency declared (per day). Some changes were made after a validation step for the questionnaire by comparing it to repeated 24-h recalls. We estimated mean consumption for a food group by adding together estimated mean consumption of all the foods included in it.

Individual total energy intakes were calculated for all women by multiplying the intake (in g per day) by the energy value of each food. Energy values were obtained from the SU.VI.MAX nutrient composition database [18, 19]. The estimated total energy intake of our women's sample varied between 1000 and $5000 \mathrm{kcal} /$ day.

In our study, we focused on categories of foods known to be rich in nutrients (vitamin $E$, vitamin $C$, vitamin $\mathrm{A}$, zinc, ...) and PUFA (n-6 FA and n-3 FA) which have a previously demonstrated association with childhood asthma and allergic diseases [20]. We chosed to examine the following categories of foods: eggs, meats, fish, cheeses, milk, cooked green vegetables, raw vegetables, grains and fruits. The foods included in each food group are listed in Table 1.
The mothers completed the first FFQ at the time of recruitment, before the 24th week of amenorrhea, indicating their usual dietary intake during the year before the pregnancy. The second FFQ was completed in the first days after delivery, and concerned their usual intake during the three final months of pregnancy. The questionnaires were completed by mothers with the assistance of the midwives if needed. For our study, we chose to examine maternal food intake during the year before the pregnancy and the three final months of pregnancy, which can be expected to reflect the mother's diet during pregnancy and which is a period during the mothers are less likely to experience nausea and vomiting and during which the organs and immune system of the fetus is still developing.

\section{Health variables}

At the age of 1,2 and 3 , the parents completed a questionnaire including questions on asthma, wheezing, allergic rhinitis, based on the validated phase I questionnaire from the International Study of Asthma and Allergies in Childhood (ISAAC) [21], and doctordiagnosed atopic dermatitis. The questionnaires were sent by mail were completed and returned back by the parents within 1 month after the distribution. If needed, parents could ask for assistance to complete the questionnaire by telephoning the midwives. Asthma was defined as parental report of doctor-diagnosis of asthma plus either one or more attacks of wheeze or asthma medication in the last 12 months. Wheeze was defined

\section{Table 1 Foods included in the food groups used for data analyses}

\begin{tabular}{|c|c|}
\hline Food group & Foods included \\
\hline Eggs & Fried eggs, omelettes, poached eggs, hard- and soft-boiled eggs \\
\hline Meats & "Grilled, roasted, or sautéed" beef, ground beef patty, pork (except charcuterie), veal, lamb, or mutton \\
\hline Poultry & Poultry (chicken, turkey, ...), rabbit \\
\hline Fish & $\begin{array}{l}\text { Fresh or frozen fish (cod, pollack, whiting, sole, trout, ...), canned fish in oil (tuna, sardines, ...), smoked or salted fish } \\
\text { (salmon, herring, ...), breaded fish, fish-based ready-made dishes, shellfish (mussels, oysters, shrimp) }\end{array}$ \\
\hline Cheeses & $\begin{array}{l}\text { Emmental, Gruyère, Comté, Beaufort, Bonbel, Babybel, Gouda, Edam, Cantal, Tommes, Morbier, St. Nectaire, Reblochon, .... } \\
\text { Brie, Camembert, Pont l'Evêque, Munster, Vacherin, St Marcelin, Caprice des Dieux-type cheese, ... } \\
\text { Roquefort, blue cheese of any origin } \\
\text { Chèvre, fresh cheese (brands such as Le Tartare, Kiri, ...) }\end{array}$ \\
\hline Milk & Whole milk, semi-skimmed milk, skimmed milk \\
\hline Fats & Butter, margarine, non-fat-reduced crème fraîche \\
\hline Cooked green vegetables & $\begin{array}{l}\text { Green beans, endives, spinach, cress, leek, cabbage, cauliflower, Brussels sprouts, broccoli, carrots, zucchini, eggplant } \\
\text { (ratatouille, ...), peas, other vegetables (turnip, chard, ...), vegetable soup, corn, pumpkin/squash, sweet potatoes, } \\
\text { soybean sprouts }\end{array}$ \\
\hline Raw vegetables & Green salad, endives, cress, spinach, grated carrot, celery, tomatoes, beets, cabbage, cucumber, radish, avocado, sprouts, ... \\
\hline Grains & Bread (white, wholewheat,...), biscotti, crispbreads, cereal \\
\hline Fruit & $\begin{array}{l}\text { Apricots, melon, mangoes, peaches, prunes, cherries, strawberries, raspberries, bananas, kiwi, citrus fruit, apples, pears, } \\
\text { grapes, other fresh fruit, dried apricots or peaches, other dried fruits }\end{array}$ \\
\hline Fruit juices & Orange juice, grapefruit juice, pineapple juice, apple juice, grape juice, etc. \\
\hline
\end{tabular}


as present if the parents answered "yes" to the question "Has your child had wheezing or whistling in the chest in the preceding 12 months?". Allergic rhinitis was defined as sneezing, nasal congestion, or rhinitis, other than with respiratory infections, accompanied by eye itching and tearing during the previous 12 months [22]. And atopic dermatitis was defined as atopic dermatitis diagnosed by a doctor. Given the uncertainty of diagnoses of asthma and allergic rhinitis in early childhood, the responses at age of 1,2 and 3 years were incorporated into calculated lifetime prevalence at age 3. Likewise, the calculated prevalence of wheezing and atopic dermatitis by the age of 3 included the responses from each year up to this age. Asthma, wheezing, allergic rhinitis and atopic dermatitis were thus defined as present at age 3 when parental responses indicated that they had been present in any of the first 3 years.

\section{Other variables}

We collected information on potential confounding factors linked to the children's health variables, including the newborn's sex, birth weight, gestational age, birth season, number of siblings at birth $(0,1-2, \geq 3)$, exclusive breastfeeding for 4 or more months, mother's age at the time of the child's birth $(<25$ years, $25-34$ years, or $>34$ years), body-mass index (BMI) before the start of the pregnancy $(18.5-24.9,25.0-29.9,30.0-34.9$, or $35.0-39.9 \mathrm{~kg} / \mathrm{m}^{2}$ ), maternal and paternal allergic history (based on a medical diagnosis of allergic diseases, including asthma, allergic rhinitis, atopic dermatitis, or food allergies), mother's and father's level of education (primary or below, secondary, university or above), household income $(\leq 3000$ euros vs. $>3000$ euros per month, the median income of the study population), city of home (Nancy or Poitiers), tobacco smoking during the pregnancy, tobacco smoking before the pregnancy, the child's exposure to environmental tobacco smoke between the ages of 0 and 3 years, humidity in the home (0 to 3 years), and supplement intake (vitamins [excluding vitamin $\mathrm{D}]$ and minerals) before and/or during the pregnancy (yes/no).

\section{Statistical analysis}

We determined the characteristics of our study population $(n=1140)$ and of the entire cohort $(n=2002)$ by calculating the frequencies of categorical variables and the means and standard deviations of continuous variables. The characteristics of our population were compared to those of the entire cohort using Chi squared tests on the frequencies of categorical variables, and Mann-Whitney $U$ tests on the means of continuous variables.
Mean consumption of foods in each food group was categorized into three tertile groups, consisting of individuals with low, moderate, and high intake of the foods in the food group. In the regression models, moderate and high intake were compared to low intake (which was used as the reference).

We analyzed the associations between the health variables and maternal food consumption by consumption level using multiple logistic regression models. We estimated odds ratios (OR) and 95\% confidence intervals $(95 \% \mathrm{CI})$ for each health variable.

Bivariate analyses were performed on each pairing of a health variable with a potential confounding factor. In a first phase, all variables whose association to a health event had a $P$ value $<0.30$ were identified. In the second phase, those involving an OR difference of at least $20 \%$ were selected and included in the multivariate models. In addition to the confounding factors included in the models on the basis of a statistically significant association with a health variable, we also selected adjustment variables based on a known relationship to asthma and allergic diseases, independently of their association with maternal food intake or their statistical association with health variables. These included: the sex of the newborn [23], maternal BMI before the pregnancy [24], birth weight [25], birth season [26], number of older siblings [27], exclusive breastfeeding [28] and daily energy intake during the pregnancy [29].

The logistic regression models were adjusted for the following factors: maternal age, maternal BMI before pregnancy, active smoking before and during pregnancy, the child's exposure to environmental tobacco smoke (between the ages of 0 and 3 years), humidity in the home (0-3 years), maternal atopy, the child's sex, birth weight, birth season, exclusive breastfeeding $\geq 4$ months, number of older siblings, mother's education, household income, supplementation before and during pregnancy and total daily energy intake.

Finally, to study the modulation of the effect of maternal food intake on child health variables by maternal atopy, we stratified the population by maternal history of asthma and allergies and tested the interaction terms (maternal food intake $\times$ maternal atopy). None of the results obtained with models stratified on maternal atopy were significant.

Separate analyses were conducted for intake in the year before pregnancy and intake during the last trimester of pregnancy.

All analyses were performed using SAS version 9.3 (SAS Institute Inc, Cary, NC, USA). All P-values $<0.05$ were considered statistically significant. 


\section{Results}

Characteristics of the population

Table 2 presents the characteristics of our population of women and their newborns $(n=1140)$ and those of the entire cohort $(n=2002)$. Our population did not differ significantly from other the entire cohort

Table 2 Characteristics of mothers and newborns in the entire cohort $(n=2002)$ vs. the study population $(n=1140)$

\begin{tabular}{|c|c|c|c|}
\hline \multirow[t]{2}{*}{ Variable } & \multicolumn{2}{|c|}{ Mean \pm SD or frequency (\%) } & \multirow[t]{2}{*}{ P-value } \\
\hline & $n=2002$ & $n=1140$ & \\
\hline \multicolumn{4}{|l|}{ Mothers } \\
\hline \multicolumn{4}{|l|}{ Center, \% } \\
\hline Poitiers & 48.35 & 55.26 & \\
\hline Nancy & 51.65 & 44.74 & 0.0002 \\
\hline Age (years) mean $\pm S D$ & $29.99 \pm 4.89$ & $30.59 \pm 4.71$ & 0.10 \\
\hline$<25, \%$ & 15.08 & 11.07 & \\
\hline $25-34, \%$ & 68.99 & 70.74 & \\
\hline$>34, \%$ & 15.93 & 18.19 & 0.04 \\
\hline $\mathrm{BMI}\left(\mathrm{kg} / \mathrm{m}^{2}\right)$, mean $\pm \mathrm{SD}$ & $26.32 \pm 4.46$ & $26.28 \pm 4.47$ & 0.69 \\
\hline Normal, \% & 45.09 & 46.09 & \\
\hline Overweight, \% & 37.82 & 37.03 & \\
\hline Moderately obese, $\%$ & 12.13 & 11.55 & \\
\hline Severely obese, $\%$ & 4.96 & 5.33 & 0.94 \\
\hline \multicolumn{4}{|l|}{ Level of education, \% } \\
\hline Primary and below & 7.56 & 4.54 & \\
\hline Secondary & 61.05 & 59.34 & \\
\hline University and above & 31.40 & 36.12 & 0.005 \\
\hline \multicolumn{4}{|l|}{ Household income, \% } \\
\hline$>3000$ euros/month & 25.82 & 29.47 & 0.03 \\
\hline Active smoking before pregnancy, \% & 36.72 & 30.93 & 0.001 \\
\hline Smoking during pregnancy (active + passive), $\%$ & 31.92 & 22.54 & 0.0001 \\
\hline Maternal atopy & 30.55 & 31.13 & 0.74 \\
\hline \multicolumn{4}{|c|}{ Supplementation with vitamins and/or trace minerals, $\%$} \\
\hline During the year preceding pregnancy only & 5.87 & 5.87 & \\
\hline During the 3rd trimester of pregnancy only & 49.70 & 49.10 & \\
\hline During both periods & 21.50 & 22.20 & \\
\hline Never & 22.94 & 22.83 & 0.98 \\
\hline Duration of gestation (WA), mean \pm SD & $39.22 \pm 1.75$ & $39.22 \pm 1.75$ & 0.97 \\
\hline \multicolumn{4}{|l|}{ Newborns } \\
\hline Sex (girl), \% & 47.45 & 46.67 & 0.67 \\
\hline Birth weight $(\mathrm{kg})$, mean $\pm \mathrm{SD}$ & $3.28 \pm 0.59$ & $3.29 \pm 0.52$ & 0.67 \\
\hline Premature, $\%^{\ddagger}$ & 5.77 & 6.05 & 0.75 \\
\hline \multicolumn{4}{|l|}{ Number of older siblings, $\%$} \\
\hline 0 & 48.60 & 48.25 & \\
\hline $1-2$ & 46.95 & 47.63 & \\
\hline$\geq 3$ & 4.45 & 4.12 & 0.88 \\
\hline \multicolumn{4}{|l|}{ Birth season, \% } \\
\hline Summer & 26.58 & 26.14 & \\
\hline Autumn & 22.22 & 22.54 & \\
\hline Winter & 21.03 & 22.28 & \\
\hline Spring & 30.17 & 29.04 & 0.82 \\
\hline Exclusive breastfeeding $\geq 4$ months, $\%$ & 13.39 & 15.09 & 0.20 \\
\hline
\end{tabular}

SD standard deviation

${ }^{+}$P-value: Chi squared test for categorical variables, Mann-Whitney U test for continuous variables; ${ }^{\ddagger}<37$ weeks of amenorrhea 
with respect to all characteristics, except for the city of residence, gestational smoking, education level, income and percentage of women aged under 25 (Table 2). No woman in our population reported type 2 diabetes diagnosed prior to pregnancy or any chronic disease other than asthma, allergic rhinitis, atopic dermatitis and food allergies.

\section{Health variables}

By the age of 3, lifetime prevalence was of $10.18 \%$ for asthma, of $35.18 \%$ for wheezing, of $12.11 \%$ for allergic rhinitis and of $43.07 \%$ for atopic dermatitis.

\section{Associations between maternal food intake before and during pregnancy and childhood asthma and allergies}

Moderate (vs. low) intake of cooked green vegetables during the year before pregnancy was inversely associated with the risk of asthma by the age of 3 [OR (95\% $\mathrm{CI})=0.60(0.34-1.03), P=0.06]$. High preconceptional intake and moderate and high intakes of cooked green vegetables during the last 3 months of pregnancy had a non-significant tendency towards a negative relationship with the risk of asthma (Table 3).

Moderate intake of eggs during pregnancy was protective against allergic [OR $(95 \% \mathrm{CI})=0.56(0.33-$ 0.93), $P=0.03)$ ] Moderate intake of eggs before pregnancy was associated with a borderline significant reduced risk of allergic rhinitis [OR $(95 \% \mathrm{CI})=0.68$ (0.44-1.04), $P=0.07]$. Moderate and high intakes of raw vegetables during pregnancy were strongly associated with a reduced risk of allergic rhinitis (respectively, OR $(95 \% \mathrm{CI})=0.44(0.26-0.74), P=0.002$ and OR $(95 \%$ $\mathrm{CI})=0.49 \quad(0.29-0.82), P=0.007)$. Similarly, moderate and high gestational intakes of cooked green vegetables were associated with a reduced risk of allergic rhinitis [respectively, OR $(95 \% \mathrm{CI})=0.61(0.37-1.00), P=0.05$ and OR $(95 \% \mathrm{CI})=0.56(0.33-0.97), P=0.04]$. High intake of raw vegetables during the year before pregnancy was protective against allergic rhinitis [OR $(95 \% \mathrm{CI})=0.62(0.40-0.98), P=0.04]$. Moderate intake of grains before pregnancy was inversely associated with the risk of allergic rhinitis [OR $(95 \% \mathrm{CI})=0.54(0.33-$ $0.88), P=0.01]$. Finally, significant associations were found between high preconceptional and gestational intakes of meats and the risk of wheezing [respectively, OR $(95 \% \mathrm{CI})=1.60(1.15-2.22), P=0.006$ and OR $(95 \%$ CI) $=1.39$ (1.01-1.92), $P=0.04]$. Moderate and high intakes of meats before pregnancy were also significantly associated with the risk of allergic rhinitis [respectively, OR $(95 \% \mathrm{CI})=1.77(1.09-2.90), P=0.02$ and OR $(95 \%$
Table 3 Adjusted associations between maternal diet before and during pregnancy and risk of wheezing in the child by the age of 3

\begin{tabular}{|c|c|c|c|c|}
\hline \multirow[t]{2}{*}{ Food category } & \multicolumn{2}{|c|}{$\begin{array}{l}\text { During the year } \\
\text { before pregnancy }\end{array}$} & \multicolumn{2}{|c|}{$\begin{array}{l}\text { During the last } \\
3 \text { months of pregnancy }\end{array}$} \\
\hline & OR $(95 \% \mathrm{CI})^{\mathrm{a}}$ & P-value & OR $(95 \% \mathrm{CI})^{\mathrm{a}}$ & P-value \\
\hline \multicolumn{5}{|l|}{ Wheezing } \\
\hline \multicolumn{5}{|l|}{ Meats } \\
\hline $\begin{array}{l}\text { Moderate vs. } \\
\text { low }\end{array}$ & $1.28(0.92-1.78)$ & 0.14 & $1.36(0.99-1.88)$ & 0.06 \\
\hline High vs. low & $1.60(1.15-2.22)$ & 0.006 & $1.39(1.01-1.92)$ & 0.04 \\
\hline \multicolumn{5}{|l|}{ Asthma } \\
\hline \multicolumn{5}{|c|}{ Cooked green vegetables } \\
\hline $\begin{array}{l}\text { Moderate vs. } \\
\text { low }\end{array}$ & $0.60(0.34-1.03)$ & 0.06 & $0.79(0.45-1.36)$ & 0.39 \\
\hline High vs. low & $0.73(0.43-1.26)$ & 0.26 & $0.89(0.51-1.57)$ & 0.69 \\
\hline \multicolumn{5}{|l|}{ Allergic rhinitis } \\
\hline \multicolumn{5}{|l|}{ Eggs } \\
\hline $\begin{array}{l}\text { Moderate vs. } \\
\text { low }\end{array}$ & $0.68(0.44-1.04)$ & 0.07 & $0.56(0.33-0.93)$ & 0.03 \\
\hline High vs. low & $0.68(0.42-1.09)$ & 0.11 & $0.71(0.43-1.18)$ & 0.19 \\
\hline \multicolumn{5}{|l|}{ Raw vegetables } \\
\hline $\begin{array}{l}\text { Moderate vs. } \\
\text { low }\end{array}$ & $0.68(0.43-1.07)$ & 0.09 & $0.44(0.26-0.74)$ & 0.002 \\
\hline High vs. low & $0.62(0.40-0.98)$ & 0.04 & $0.49(0.29-0.82)$ & 0.007 \\
\hline \multicolumn{5}{|l|}{ Grains } \\
\hline $\begin{array}{l}\text { Moderate vs. } \\
\text { low }\end{array}$ & $0.54(0.33-0.88)$ & 0.01 & $1.32(0.80-2.18)$ & 0.28 \\
\hline High vs. low & $0.77(0.49-1.22)$ & 0.26 & $0.95(0.55-1.63)$ & 0.85 \\
\hline \multicolumn{5}{|c|}{ Cooked green vegetables } \\
\hline $\begin{array}{l}\text { Moderate vs. } \\
\text { low }\end{array}$ & $1.02(0.64-1.63)$ & 0.94 & $0.61(0.37-1.00)$ & 0.05 \\
\hline High vs. low & $1.05(0.65-1.69)$ & 0.86 & $0.56(0.33-0.97)$ & 0.04 \\
\hline \multicolumn{5}{|l|}{ Meats } \\
\hline $\begin{array}{l}\text { Moderate vs. } \\
\text { low }\end{array}$ & $1.77(1.09-2.90)$ & 0.02 & $1.00(0.60-1.67)$ & 0.99 \\
\hline High vs. low & $1.63(1.00-2.67)$ & 0.05 & $0.98(0.50-1.42)$ & 0.49 \\
\hline \multicolumn{5}{|l|}{ Atopic dermatitis } \\
\hline \multicolumn{5}{|l|}{ Meats } \\
\hline $\begin{array}{l}\text { Moderate vs. } \\
\text { low }\end{array}$ & $1.02(0.75-1.39)$ & 0.90 & $0.90(0.64-1.25)$ & 0.53 \\
\hline High vs. low & $1.33(0.98-1.81)$ & 0.07 & $1.09(0.77-1.53)$ & 0.64 \\
\hline
\end{tabular}

OR odds ratio, 95\% Cl 95\% confidence interval

a Adjusted for maternal age, maternal pre-pregnancy mother's BMI, mother's active smoking before and during pregnancy, child's exposure to environmental tobacco smoke (ages 0 to 3 years), humidity in the home (ages 0 to 3 years), maternal atopy, child's sex, birth season, birth weight, exclusive breastfeeding $\geq 4$ months, number of older siblings, mother's education, household income, supplementation before and during pregnancy, and total daily energy intake (before or during pregnancy)

$\mathrm{CI})=1.63(1.00-2.67), P=0.05]$. A borderline significant association was found between high intake of meats 
before pregnancy and the risk of atopic dermatitis (Table 3).

\section{Discussion}

In this prospective birth cohort study of French motherchild pairs, we found beneficial associations between cooked green vegetable consumption before pregnancy and childhood asthma; consumption of eggs and raw vegetables before and during pregnancy, consumption of grains before pregnancy, and consumption of cooked green vegetables during pregnancy and allergic rhinitis. To our knowledge, this study is the first to show a significant positive association between meat intake during the preconceptional period and a risk of wheezing, allergic rhinitis and atopic dermatitis in young children.

The beneficial effect of early regular consumption of cooked green vegetables, eggs, raw vegetables and grains before or during pregnancy on asthma, wheezing and allergic rhinitis in children may partly be due to the relatively high levels of antioxidants in these foods, but also to other nutrients found in these foods, notably vitamin $\mathrm{D}$ and $\mathrm{n}-3$ (omega-3) polyunsaturated fatty acids (n-3 FA), which have been proven to have a protective effect against asthma and allergic diseases [30, 31]. Experimental models have shown that oxidant molecules can induce asthmatic reactions by provoking the release of proinflammatory mediators [32]. As a result, a low antioxidant diet may be associated to altered pulmonary development and consequently promote the development of wheezing and reduced respiratory function later in life. Certain antioxidant nutrients, such as vitamin E, flavonoids and selenium, in addition to their antioxidant properties, have immunomodulatory properties [33], which are protective against asthma and allergic diseases.

In addition, there is some evidence that early postnatal introduction of foods such as peanuts, fish and eggs might be beneficial in preventing allergies [34, 35]. More recently, a study found that a higher maternal intake of food allergens, including peanut and wheat, during early pregnancy was associated with a lower risk of allergy and asthma in the offspring at 8 years of age [36]. In our study, we showed that preconceptional and gestational exposure of potential allergens, including egg allergens, may also be beneficial for allergic rhinitis prevention, however results before pregnancy were borderline significant and only moderate intake of eggs during pregnancy may lower the risk of developing allergic rhinitis by the age of 3. In addition, we found that high consumption of eggs before pregnancy was inversely associated with the risk of wheezing, which may be an allergic disease symptom.

Regarding the associations found with meat intake, our results confirm findings of a previous study in children that showed a significant positive relationship between maternal meat intake during pregnancy and the prevalence of wheeze in the first year of life [9]. In addition, we found a significant association between high preconceptional intake of meats and risk of allergic rhinitis, which has not been demonstrated previously. One potential explanation of the association found with high meat intake is that some consituents of meat may affect the future development of symptoms such as wheezing and allergic diseases. Carcinogenic compounds, such as heterocyclic amines and polycyclic aromatic hydrocarbons are produced as meat is cooked at high temperatures [37]. In addition, meat intake results in exposure to $\mathrm{N}$-nitroso compounds, which can form endogenously [38] and exogenously in nitrite-preserved meats [39]. As a result, these components found in meat may affect fetal immune system, although there is currently no epidemiological evidence of association between these carcinogens and wheeze and allergic diseases. Alternatively, meat intake might be an indicator of a specific maternal dietary pattern that may be related to an increased risk of wheeze and allergic diseases in children. Additionally, it may be possible that some unknown non-dietary factors related to meat intake may have confounded the observed associations.

Our results failed to reveal beneficial effects of certain categories of foods that have been demonstrated in previous studies to be protective against asthma and allergic diseases, notably fruit [40] and fish [40, 41]. One hypothesis that might explain this lack of association relates to recent and rapid adaptations by the agro-food system. With changes in lifestyles and technological and scientific advances, there has been a proliferation of new processed foods to respond to consumer demand. Many food products have become easier to store, transport, and conserve, designed to have a longer shelf life and to be prepared simply and quickly. However, this processing may have changed the nutritional content of certain foods. Some results suggest that the nutrient content of processed foods has changed, and may be lower in some vitamins and trace minerals [42]. Moreover, maternal fish consumption can be a source of fetal exposure to mercury [43] and other toxic substances [44]. The beneficial effect of fish might thus be offset by the presence of toxic contamination.

An original aspect of the present study is our examination of the relationship between childhood asthma and allergic diseases and maternal food intake during the year preceding the pregnancy. The significant associations that were found suggest that maternal nutritional factors before pregnancy may also play an important protective role against childhood asthma and allergic diseases. This observation raises the hypothesis that maternal diet during the periconceptual period, 
which is an important critical life stage, may have an impact on the epigenetic programming involved in the prevention (or early development, in the case of essential nutrient deficiencies) of asthma and allergic diseases. The nutrients in the foods that mothers consume before they become pregnant, at least during the year before pregnancy, may cause epigenetic changes and affect child health. One recent study showed that maternal supplementation with micronutrients during the periconceptual period was associated with changes in the epigenome of newborns [45]. Micronutrients appear to be involved in the methylation of some immune system genes. These epigenetic changes seem to be transmitted to the fetus during pregnancy, modifying genes involved in the development of the immune system, particularly in utero and in early childhood [45].

However, our study has some limitations. The use of FFQs to assess food intake can lead to errors as it is based on self-report and may be subject to memory bias, as well as misclassification bias (under-/over-estimation) when the women have difficulty assessing their intake, although if we adjusted for mother's BMI. Moreover, as often in epidemiological study, we cannot conclude that there is a causal relationship between the consumption of certain food groups and child health. It could also be that lifestyle and personal health practices during pregnancy, factors that we were not able to assess, play an important role in the occurrence of allergic diseases. However, numerous results suggest that exposure to prenatal factors, including maternal diet, may have a greater influence on the development of asthma and of allergic diseases such as allergic rhinitis [46] by playing a role in the "programming" of fetal lung and immune development [47, 48]. In addition, the absence of significant associations between asthma and intake of food categories might be due to the low prevalence of this outcome, consequently limiting the power to detect a relationship between intake of food categories and the outcome. And finally, data on the children's health were obtained through parental report via a questionnaire, which could also have led to misclassification bias. However, these questionnaires were based on the validated ISAAC questionnaires, decreasing the risk of such biases.

\section{Conclusions}

The present study highlighted associations between maternal food intake before and during pregnancy and asthma and some allergic diseases in childhood.

Two public health interventions that can contribute to preventing asthma and allergic diseases in childhood are to provide women desiring pregnancy and pregnant women with recommendations on diet, notably concerning products with an effect on the development of allergic diseases and to promote healthy lifestyles. However, understanding the mechanisms by which dietary compounds promote or inhibit the development of allergies is essential to suggest specific and personalized guidelines for food avoidance or intake. Especially, a better understanding of the mechanisms relating metabolic and allergic diseases is crucial.

\section{Abbreviations}

EDEN: Etude des Déterminants pré et post natals du développement et de la santé de I'Enfant; ISAAC: International Study of Asthma and Allergies in Childhood; OR: odds ratio; Cl: confidence interval; SD: standard deviation.

\section{Acknowledgements}

We are extremely grateful to all the families who took part in this study, the midwives for recruiting and following them, and the whole EDEN team.

\section{Authors' contributions}

IAM, AF and BDLG conceived EDEN; NB conceived this study and performed statistical analyses; NB, AF, BDLG and IAM interpreted the data; NB drafted the manuscript; JJ, AF, BDLG, JC, AMM and IAM contributed to the critical revision of the manuscript. All authors read and approved the final manuscript.

\section{Funding}

We acknowledge all the funding sources for the EDEN study: Fondation pour la Recherche Médicale (FRM), the French Ministry of Research's IFR program, the INSERM Nutrition Research Program, French Ministry of Health's Perinatality Program, the French National Institute for Population Health Surveillance (INVS), Paris-Sud University, the French National Institute for Health Education (INPES), Nestlé, Mutuelle Générale de l'Education Nationale (MGEN), the French-language association for the study of diabetes and metabolism (ALFEDIAM), and the National Research Agency (ANR). The funders had no role in study design, data collection and analysis, decision to publish, or preparation of the manuscript.

\section{Availability of data and materials}

The datasets used and/or analysed during the current study are available from the corresponding author on reasonable request.

\section{Ethics approval and consent to participate}

The ethical committees who approved the study are: Comite Consultatif pour la Protection des Personnes dans la Recherche Biomédicale, Le Kremlin-Bicêtre University hospital, and Commission Nationale de l'Informatique et des Libertés. The study was approved on 12 December 2002. Written consent was obtained from the mother for herself at the beginning of the study and from both parents for the newborn child after delivery.

\section{Consent for publication}

Not applicable.

\section{Competing interests}

The authors declare that they have no competing interests.

\section{Author details}

${ }^{1}$ Epidemiology of Allergic and Respiratory Diseases Department (EPAR), Pierre Louis Institute of Epidemiology and Public Health (IPLESP UMRS 1136), Saint-Antoine Medical School, Sorbonne Université and INSERM, 27 Rue Chaligny, 75571 Paris Cedex 12, France. ${ }^{2}$ Département d'Allergologie, Hôpital Trousseau AP-HP-UPMC Paris 6, Paris, France. ${ }^{3}$ Department of General Practice, Medical School Saint Antoine, Sorbonne Université, 75012 Paris, France. ${ }^{4}$ INSERM, UMR1153 Center for Research in Epidemiology and StatisticS (CRESS), Research Team on Early Life Origins of Heath (EAROH), Paris, France. ${ }^{5}$ Paris Descartes University, Paris, France. ${ }^{6}$ INRA, U1 125 Center for Research in Epidemiology and StatisticS (CRESS), Research Team on Early Life Origins of Heath (EAROH), Paris, France. 
Received: 20 February 2019 Accepted: 13 June 2019

Published online: 22 June 2019

\section{References}

1. Baiz N, Annesi-Maesano I. Is the asthma epidemic still ascending? Clin Chest Med. 2012;33:419-29.

2. Pawankar R. Allergic diseases and asthma: a global public health concern and a call to action. World Allergy Organ J. 2014;7:1-3.

3. Beckhaus AA, Garcia-Marcos L, Forno E, Pacheco-Gonzalez RM, Celedon JC, Castro-Rodriguez JA. Maternal nutrition during pregnancy and risk of asthma, wheeze, and atopic diseases during childhood: a systematic review and meta-analysis. Allergy. 2015;70:1588-604.

4. Prescott SL. Early origins of allergic disease: a review of processes and influences during early immune development. Curr Opin Allergy Clin Immunol. 2003;3:125-32.

5. Zazzo J. Oligoéléments et grossesse. Repr Hum Horm. 1995;8:539-45.

6. Harding JE. The nutritional basis of the fetal origins of adult disease. Int J Epidemiol. 2001;30:15-23

7. Devereux G, Barker RN, Seaton A. Antenatal determinants of neonatal immune responses to allergens. Clin Exp Allergy. 2002;32:43-50.

8. Julia V, Macia L, Dombrowicz D. The impact of diet on asthma and allergic diseases. Nat Rev Immunol. 2015;15:308-22.

9. Chatzi L, Kogevinas M. Prenatal and childhood Mediterranean diet and the development of asthma and allergies in children. Public Health Nutr 2009:12:1629-34.

10. Erkkola M, Nwaru BI, Kaila M, Kronberg-Kippila C, Ilonen J, Simell O, Veijola R, Knip M, Virtanen SM. Risk of asthma and allergic outcomes in the offspring in relation to maternal food consumption during pregnancy: a Finnish birth cohort study. Pediatr Allergy Immunol. 2012;23:186-94.

11. Oien T, Storro O, Johnsen R. Do early intake of fish and fish oil protect against eczema and doctor-diagnosed asthma at 2 years of age? A cohort study. J Epidemiol Commun Health. 2010;64:124-9.

12. Willers SM, Wijga AH, Brunekreef B, Kerkhof M, Gerritsen J, Hoekstra MO, de Jongste JC, Smit HA. Maternal food consumption during pregnancy and the longitudinal development of childhood asthma. Am J Respir Crit Care Med. 2008;178:124-31.

13. Heude B, Forhan A, Slama R, Douhaud L, Bedel S, Saurel-Cubizolles MJ, Hankard R, Thiebaugeorges O, De Agostini M, Annesi-Maesano I, Kaminski M, Charles MA, Group Em-ccs. Cohort profile: the EDEN mother-child cohort on the prenatal and early postnatal determinants of child health and development. Int J Epidemiol. 2016;45:353-63.

14. de Lauzon B, Romon M, Deschamps V, Lafay L, Borys JM, Karlsson J, Ducimetiere P, Charles MA. The Three-Factor Eating Questionnaire-R18 is able to distinguish among different eating patterns in a general population. J Nutr. 2004;134:2372-80.

15. Deschamps V, de Lauzon-Guillain B, Lafay L, Borys JM, Charles MA, Romon M. Reproducibility and relative validity of a food-frequency questionnaire among French adults and adolescents. Eur J Clin Nutr. 2009;63:282-91.

16. SU.VI.MAX, editor. Portions alimentaires-Manuel photos pour l'estimation des quantités. Paris; 2002

17. Lafay L ML, Six MA, Calamassi-Tran G, Hercberg S, Volatier JL, Castebon K, Martin A. Etude de validation d'un carnet de consommation alimentaire de 7 jours pour l'enquête INCA2-ENNS. Actes des Journées de méthodologie statistique 2002; 2002.

18. Le Hercberg S. programme national nutrition santé (PNNS). Arch Pediatr Adolesc Med. 2003;10:554-6.

19. Le Moullec NDM, Preziosi P, Monteiro P, Valeix P, Rolland Cachera MF, Courcy G, Christides JP, Cherouvrier F, Galan P, Hercberg S. Validation of photographic document used to estimate the amounts of foods eaten by subjects in the SU.VI.MAX study. Cah Nutr Diet. 1996;31:158-64.

20. Devereux G, Turner SW, Craig LC, MCNeill G, Martindale S, Harbour PJ, Helms PJ, Seaton A. Low maternal vitamin E intake during pregnancy is associated with asthma in 5-year-old children. Am J Respir Crit Care Med. 2006;174:499-507.

21. Worldwide variations in the prevalence of asthma symptoms. The international study of asthma and allergies in childhood (ISAAC). Eur Respir J. 1998;12:315-35.
22. Asher MI, Keil U, Anderson HR, Beasley R, Crane J, Martinez F, Mitchell EA, Pearce N, Sibbald B, Stewart AW, et al. International Study of Asthma and Allergies in Childhood (ISAAC): rationale and methods. Eur Respir J. 1995;8:483-91

23. Ninan TK, Russell G. Respiratory symptoms and atopy in Aberdeen school children: evidence from two surveys 25 years apart. BMJ. 1992;304:873-5.

24. Patel SP, Rodriguez A, Little MP, Elliott P, Pekkanen J, Hartikainen AL, Pouta A, Laitinen J, Harju T, Canoy D, Jarvelin MR. Associations between prepregnancy obesity and asthma symptoms in adolescents. J Epidemiol Commun Health. 2012;66:809-14.

25. Sin DD, Spier S, Svenson LW, Schopflocher DP, Senthilselvan A, Cowie $\mathrm{RL}$, Man SF. The relationship between birth weight and childhood asthma: a population-based cohort study. Arch Pediatr Adolesc Med. 2004:158:60-4.

26. Harley KG, Macher JM, Lipsett M, Duramad P, Holland NT, Prager SS, Ferber J, Bradman A, Eskenazi B, Tager IB. Fungi and pollen exposure in the first months of life and risk of early childhood wheezing. Thorax. 2009;64:353-8.

27. Kurosaka F, Terada T, Tanaka A, Nakatani Y, Yamada K, Nishikawa J, Oka K, Takahashi H, Mogami A, Yamada T, Nakano T, Shima M, Nishio H. Risk factors for wheezing, eczema and rhinoconjunctivitis in the previous 12 months among six-year-old children in Himeji City, Japan: food allergy, older siblings, day-care attendance and parental allergy history. Allergol Int. 2011;60:317-30.

28. Kramer MS. Breastfeeding and allergy: the evidence. Ann Nutr Metab. 2011;59(Suppl 1):20-6.

29. Ushiyama Y, Matsumoto K, Shinohara M, Wakiguchi H, Sakai K, Komatsu T, Yamamoto S. Nutrition during pregnancy may be associated with allergic diseases in infants. J Nutr Sci Vitaminol (Tokyo). 2002:48:345-51.

30. Litonjua AA, Weiss ST. Is vitamin D deficiency to blame for the asthma epidemic? J Allergy Clin Immunol. 2007;120:1031-5.

31. Nwaru BI, Erkkola M, Lumia M, Kronberg-Kippila C, Ahonen S, Kaila M, Ilonen J, Simell O, Knip M, Veijola R, Virtanen SM. Maternal intake of fatty acids during pregnancy and allergies in the offspring. Br J Nutr. 2012;108:720-32

32. Caramori G, Papi A. Oxidants and asthma. Thorax. 2004;59:170-3.

33. Kremmyda LS, Vlachava M, Noakes PS, Diaper ND, Miles EA, Calder PC. Atopy risk in infants and children in relation to early exposure to fish, oily fish, or long-chain omega-3 fatty acids: a systematic review. Clin Rev Allergy Immunol. 2011:41:36-66.

34. Du Toit G, Katz Y, Sasieni P, Mesher D, Maleki SJ, Fisher HR, Fox AT, Turcanu V, Amir T, Zadik-Mnuhin G, Cohen A, Livne I, Lack G. Early consumption of peanuts in infancy is associated with a low prevalence of peanut allergy. J Allergy Clin Immunol. 2008;122:984-91.

35. Koplin JJ, Osborne NJ, Wake M, Martin PE, Gurrin LC, Robinson MN, Tey D, Slaa M, Thiele L, Miles L, Anderson D, Tan T, Dang TD, Hill DJ, Lowe AJ, Matheson MC, Ponsonby AL, Tang ML, Dharmage SC, Allen KJ. Can early introduction of egg prevent egg allergy in infants? A population-based study. J Allergy Clin Immunol. 2010;126:807-13.

36. Bunyavanich S, Rifas-Shiman SL, Platts-Mills TA, Workman L, Sordillo JE, Camargo CA Jr, Gillman MW, Gold DR, Litonjua AA. Peanut, milk, and wheat intake during pregnancy is associated with reduced allergy and asthma in children. J Allergy Clin Immunol. 2014;133:1373-82.

37. Sinha R, Norat T. Meat cooking and cancer risk. IARC Sci Publ. 2002;156:181-6.

38. Hughes R, Cross AJ, Pollock JR, Bingham S. Dose-dependent effect of dietary meat on endogenous colonic N-nitrosation. Carcinogenesis. 2001;22:199-202.

39. Mirvish SS, Haorah J, Zhou L, Clapper ML, Harrison KL, Povey AC. Total $\mathrm{N}$-nitroso compounds and their precursors in hot dogs and in the gastrointestinal tract and feces of rats and mice: possible etiologic agents for colon cancer. J Nutr. 2002;132:3526S-9S.

40. Willers SM, Devereux G, Craig LC, MCNeill G, Wijga AH, Abou El-Magd W, Turner SW, Helms PJ, Seaton A. Maternal food consumption during pregnancy and asthma, respiratory and atopic symptoms in 5-year-old children. Thorax. 2007;62:773-9.

41. Romieu I, Torrent M, Garcia-Esteban R, Ferrer C, Ribas-Fito N, Anto JM, Sunyer J. Maternal fish intake during pregnancy and atopy and asthma in infancy. Clin Exp Allergy. 2007;37:518-25.

42. Thomas D. A study on the mineral depletion of the foods available to us as a nation over the period 1940 to 1991. Nutr Health. 2003:17:85-115. 
43. Bjornberg KA, Vahter M, Petersson-Grawe K, Glynn A, Cnattingius S, Darnerud PO, Atuma S, Aune M, Becker W, Berglund M. Methyl mercury and inorganic mercury in Swedish pregnant women and in cord blood: influence of fish consumption. Environ Health Perspect. 2003;111:637-41.

44. Ramalhosa MJ, Paiga P, Morais S, Ramos S, Delerue-Matos C, Oliveira MB. Polycyclic aromatic hydrocarbon levels in three pelagic fish species from Atlantic Ocean: inter-specific and inter-season comparisons and assessment of potential public health risks. Food Chem Toxicol. 2012:50:162-7.

45. Khulan B, Cooper WN, Skinner BM, Bauer J, Owens S, Prentice AM, Belteki G, Constancia M, Dunger D, Affara NA. Periconceptional maternal micronutrient supplementation is associated with widespread gender related changes in the epigenome: a study of a unique resource in the Gambia. Hum Mol Genet. 2012;21:2086-101.
46. Kumar R. Prenatal factors and the development of asthma. Curr Opin Pediatr. 2008:20:682-7.

47. Langley-Evans S. Fetal programming of immune function and respiratory disease. Clin Exp Allergy. 1997;27:1377-9.

48. Langley-Evans SC, Carrington LJ. Diet and the developing immune system. Lupus. 2006;15:746-52.

\section{Publisher's Note}

Springer Nature remains neutral with regard to jurisdictional claims in published maps and institutional affiliations.
Ready to submit your research? Choose BMC and benefit from:

- fast, convenient online submission

- thorough peer review by experienced researchers in your field

- rapid publication on acceptance

- support for research data, including large and complex data types

- gold Open Access which fosters wider collaboration and increased citations

- maximum visibility for your research: over 100M website views per year

At BMC, research is always in progress.

Learn more biomedcentral.com/submissions 